\title{
PROTON PUMP INHIBITORS FOR STRESS ULCER BLEEDING PROPHYLAXIS IN CRITICALLY ILL PATIENTS: A COST ANALYSIS STUDY
}

\author{
RANO K SINURAYA ${ }^{1 *}$, SHARON GONDODIPUTRO², HENNI DJUHAENI²
}

${ }^{1}$ Department of Pharmacology and Clinical Pharmacy, Faculty of Pharmacy, Universitas Padjadjaran, Indonesia. ${ }^{2}$ Department of Public Health, Faculty of Medicine, Universitas Padjadjaran, Indonesia. Email: r.k.sinuraya@unpad.ac.id

Received: 21 October 2016, Revised and Accepted: 30 January 2017

\section{ABSTRACT}

Objective: Stress ulcer prophylaxis is generally administered for the prevention stress-related mucosal disease (SRMD) in critically ill patients. Proton pump inhibitors (PPIs) are most commonly prescribed in preventing bleeding from SRMD. Pantoprazole intravenous (iv) and omeprazole iv are the most effective, but clinically effective is not always efficient. This study aimed to investigate whether the most efficient PPIs for prophylaxis in intensive care unit settings.

Methods: An observational study was conducted on June 2014 with comparative design by using medical records in January 2012 -November 2014 in a private hospital in Bandung city. Both retrospective and prospective data collection was performed in this study. Paired t-test analysis was used to compare average cost of the drugs with significant level $\mathrm{p}<0.05$.

Results: The results showed the average cost of pantoprazole iv 458.142 Indonesian Rupiah (IDR)/patient and omeprazole iv 575.573 IDR/patient; there were significant differences of average drug cost between pantoprazole iv and omeprazole iv $(\mathrm{p}=0.0085)$.

Conclusion: Both pantoprazole iv and omeprazole iv were effective, but pantoprazole iv had been found more efficient.

Keywords: Cost analysis, Proton pump inhibitors, Prophylaxis, Stress ulcer bleeding.

(C) 2017 The Authors. Published by Innovare Academic Sciences Pvt Ltd. This is an open access article under the CC BY license (http://creativecommons. org/licenses/by/4. 0/) DOI: http://dx.doi.org/10.22159/ajpcr.2017.v10s2.20413

\section{INTRODUCTION}

Stress ulcer is superficial erosions of gastric mucosa acutely arising from physiological stress experienced by critical ill patient with clinical manifestation is bleeding. Research was conducted by Stollman and Metz [1], MacLaren and Campbell [2], and Barletta et al. [3] stated that the increasing of stress ulcer bleeding which reach $5 \%$ could lead to death, increasing length of stay (LOS) (4-8 days), morbidity (more than $49 \%$ ), and mortality, and also cost of health care.

Stress ulcer is most often found in patients of the intensive care unit (ICU), which achieve $90 \%$ of total ICU patients. It could be happened because the ICU patients undergoing splanchnic hypoperfusion, using ventilator, taking opiates, and sedatives medicines [4]. Research conducted by Cook et al. [5] stated that administration of stress ulcer prophylaxis (SUP) in patients can lower the risk of bleeding by up to $50 \%$. SUP is most often used for stress-induced ulcer bleeding prevention, e.g., stomach acid neutralizer (antacid), proton pump inhibitor (PPI), histamine-2 receptor antagonist, sucralfate, and misoprostol. The previous studies were conducted by Harty and Ancha [6], Schupp et al. [7], Barkun et al. [8], and Barletta and Sclar [9] proved that PPI was more effective among all prophylactic agents in preventing stress ulcer bleeding.

PPIs have five categories; they are omeprazole, pantoprazole, lansoprazole, rabeprazole, and esomeprazole [4]. All these categories are commonly used in ICU settings with no guidelines available, so physicians can prescribe this medicines freely. It became a high-cost problem to a hospital and inefficient.

\section{METHODS}

An observational study with retrospective and prospective data was conducted on June 2014 with comparative design using medical records and drug cost data in January 2012-November 2014 in a private hospital in Bandung city.

\section{Population}

Patients medical records included were $\geq 18$ years old with risk factor of stress ulcer (e.g., failed to breath, coagulopathy, hypotension, sepsis, liver failure, kidney failure, using glucocorticoid and anticoagulant, and using nasogastric tube), patient who used PPI injection. Exclusion criteria were patients $<18$ years old, admission to a non-ICU floor, having an active gastrointestinal (GI) bleed before the start of therapy, having a history of gastroesophageal reflux disease, patient who died in the ICU.

\section{Data collection}

Data collected included: (1) The use of PPI before admission and the indication for the use, (2) the agent used for prophylaxis, (3) changes in SUP therapy and the reason for the changes, (4) patient outcomes including development of a GI bleed, (5) LOS in ICU, and (6) cost of medicines based on payer perspective.

Clinical outcome

Treatment success was defined as the patient not experiencing a GI bleed and also patient was alive when came out from ICU.

\section{Economic outcome}

Economic outcomes were measured by drug costs directly related to SUP.

Analysis

Data were analyzed statistically using SPSS.17.

\section{RESULTS}

This research was approved by Ethics Committee, Faculty of Medicine Universitas Padjadjaran, Indonesia. Data were collected from medical records and billing system of the hospital. A number of 398 medical records were collected and founded that 245 patients using pantoprazole with 88 patients succeed, 127 patients using omeprazole intravenous (iv) with 49 patients succeed, and 3 patients (all succeed) who change from pantoprazole iv to omeprazole iv. 
Patient characteristics

Based on data, it can be inferred that only 140 patients who had succeeded with PPI as SUP (Table 1).

\section{Outcome therapy}

The outcomes analysis only presented the outcome between pantoprazole iv and omeprazole iv using Chi-square analysis (Table 2).

\section{Cost analysis}

In this study, cost-efficiency analysis was performed by looking at the difference of average drug costs per patient (Fig. 1).

A transformation data were performed with logarithmic approach (slope $=0.846$, power $=0.154$ ). Average medication costs were analyzed using matching principle with unrelated paired t-test, so data will be more homogeneous and bias can be minimized. Matching criteria were based on LOS of the patient. Based on LOS, 49 data were selected to be analyzed with unrelated paired t-text (Table 3 ).

\section{DISCUSSION}

In ICU setting commonly iv PPI is the best choice because of the effectivity and easier to administer. Based on previous studies, proven that PPI gave the best results and the most effective among other SUP in ICU setting [1]. However, the hospitals faced inefficiency problem due to lacking of SUP guidelines and which PPI should be used. In this hospital, the using of PPI was varied and based on the physicians' decision. However, PPI is quite expensive compared with others SUP. They could not provide all kind of PPI because of high cost.

In this study, cost analysis was performed to average cost of PPI per patient. We only used drug cost because PPI only as prophylaxis and not for the main diseases or diagnosis. If we used all medication cost, it will be varied among all patients. Prophylactic medication cost is the total

Table 1: Patient characteristics

\begin{tabular}{llll}
\hline Item & $\begin{array}{l}\text { Pantoprazole } \\
\text { iv (n=88) }\end{array}$ & $\begin{array}{l}\text { Omeprazole } \\
\text { iv }(\mathbf{n = 4 9 )}\end{array}$ & $\begin{array}{l}\text { Pantoprazole } \\
\text { iv change to } \\
\text { omeprazole } \\
\text { iv (n=3) }\end{array}$ \\
\hline $\begin{array}{l}\text { Age (year) } \\
\text { Median (SD) }\end{array}$ & $58(15.36)$ & $61(17.92)$ & $33(9.86)$ \\
$\quad$ Range & $18-86$ & $18-87$ & $27-45$ \\
$\begin{array}{l}\text { Gender, n (\%) } \\
\text { Male }\end{array}$ & $46(52.3)$ & $26(53.1)$ & $3(100)$ \\
$\begin{array}{l}\text { Fermale } \\
\text { Lenght of stay }\end{array}$ & $42(42.7)$ & $23(46.9)$ & $0(0)$ \\
(days) & & & $3(0.57)$ \\
$\quad \begin{array}{l}\text { Median } \\
\text { Range }\end{array}$ & 4 & $3-19$ & $3-4$ \\
\hline
\end{tabular}

iv: Intravenous, SD: Standard deviation

Table 2: Outcome therapy analysis

\begin{tabular}{lllll}
\hline \multirow{2}{*}{ SUP } & \multicolumn{2}{l}{ Outcome, $\mathbf{n}(\%)$} & Total & p (one tailed) \\
\cline { 2 - 3 } & Succeed & Failed & & \\
\hline Pantoprazole iv & $88(35.9)$ & $157(64.1)$ & 245 & 0,347 \\
Omeprazole iv & $49(38.6)$ & $78(61.4)$ & 127 & \\
\hline
\end{tabular}

SUP: Stress ulcer prophylaxis, iv: Intravenous cost of the drugs (PPIs) that used as SUP during patient treated in the ICU until the patient is out of ICU.

Based on the age, patients who received prophylactic aged generally above 50 years old. On the other hand, characteristics of gender between male and female who received prophylaxis was not much different neither pantoprazole iv nor omeprazole iv. The previous study conducted by Schupp et al. [7] and Araujo [10] also stated that there was no meaningful difference between the age and gender in the SUP administration. This is because based on the American Society of Health-System Pharmacist [4], prophylaxis can be given after the patient is examined about physical condition and risk factors when they came to ICU. Adjustment of dose and dosage form of prophylaxis is also needed before administered.

In general, in this hospital, patients who using prophylaxis are postoperative patients, patients with cardiovascular disorders, lung and kidney disorder, patients with ventilator, as well as patients with risk factors of sepsis. This finding was same with previous research that conducted by Barletta et al. [3], Madsen et al. [11], and Harty and Ancha [6] that patients with disorders of the cardiovascular, pulmonary, and post-operative stress ulcer was susceptible therefore should be given prophylactic. The postponement of SUP can lead to bleeding that will increase the cost to address that bleeding.

Based on the data, there were 375 ICU patients who had risked stress ulcer and got SUP. However, only 140 (37\%) patient who did not experience with bleeding and/or out from the ICU alive. This finding was in line with the research conducted by Stollman and Metz [1] and MacLaren and Campbell [2]; the incidence of stress ulcer in ICU can increase the risk of death of $49 \%$ and mortality by up to four times. Research conducted by Barletta and Sclar [9] stated that the incidence of stress ulcer bleeding occurred which impacted may extend LOS/LOS in the ICU about 4-8 days and also increase the cost. All of the patient in this study who received PPI as SUP have LOS around 3-19 days.

In Table 2, It can be seen that there was not significant differences between the outcome of pantoprazole iv and omeprazole iv as SUP $(p=0,347)$. This is because even both of these drugs have different pharmacology profile but most likely there was no difference in effectiveness between both of them. Both of these drugs have the same

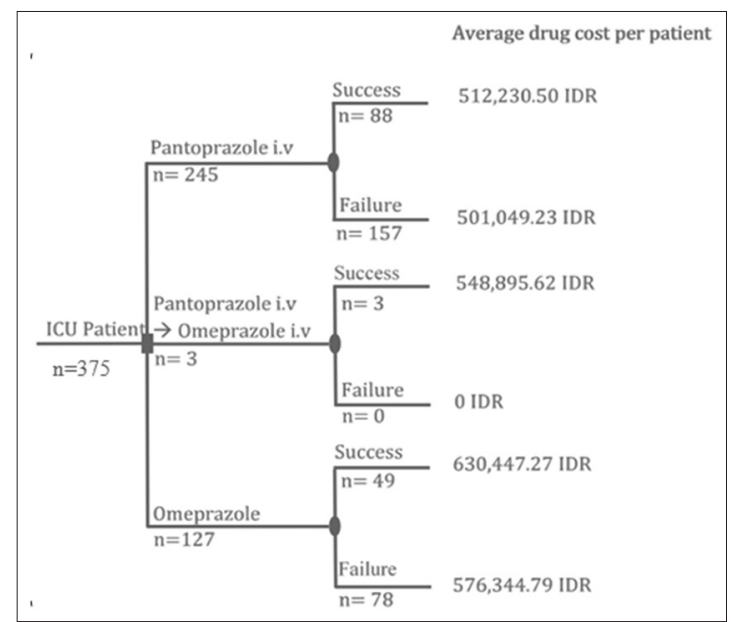

Fig. 1: Average cost of each treatment IDR: Indonesian Rupiah

Table 3: Paired t-test of medication cost

\begin{tabular}{llll}
\hline SUP & $\mathbf{n}$ & Mean (SD) & Mean differences (CI 95\%) \\
\hline Pantoprazole iv & 49 & $5.5836(0.26)$ & $0.1631(0.0707-0.2556)$ \\
Omeprazole iv & 49 & $5.7468(0.22)$ & \\
\hline
\end{tabular}

SUP: Stress ulcer prophylaxis, iv: Intravenous, SD: Standard deviation 
mechanism, they are inhibiting the secretion of gastric acid. However, both of these drugs have different category of drug interactions. Therefore, we suggest that administering of this drug should be based on the guidelines and considered other drugs so that patients will not get drug interactions when take one of this medicine $[12,13]$. The difference category of interaction is an important consideration in the administering of SUP. Harty and Ancha [6] stated that in spite of pantoprazole and omeprazole have the same effectiveness, but they have different aspects of pharmacokinetics. Pantoprazole does not have interaction when metabolized in the liver but omeprazole had a very varied interaction.

Effectivity and safety are not the only consideration in drug choice, cost also become a major problem [14]. Fig. 1 showed the decision diagram of SUP costs per patient based on the clinical outcome. It can be seen that the average of drug costs per patient who given pantoprazole iv were smaller than omeprazole iv. The difference in average drug costs per patient for the pantoprazole iv and omeprazole iv are approximately 99,631 Indonesian Rupiah (IDR). However, if a replacement therapy of pantoprazole iv to omeprazole iv was performed, it could increase the average drug costs per patient about 25,237 IDR. This decision diagram is closely related with the opportunity cost. Opportunity cost is the opportunity that was lost due to the selection of an alternative. When associated with SUP, the selection of the patients who given pantoprazole iv will experience the opportunity cost against omeprazole iv and vice versa. Therefore, based on the results, a decision of a therapy not only impacted the opportunity cost but also cost savings of a prophylaxis. Based on the calculation, it was obtained by administering pantoprazole iv can be carried out cost saving of SUP around 99,631 IDR.

Cost efficiency analysis or cost minimization analysis used to compare average costs among two or more intervention with same therapeutic results (outcomes) $[14,15]$. Based on the statistical analysis, it can be seen that the average cost of pantoprazole iv were lower than omeprazole iv so that pantoprazole iv was more efficient or cost minimize compared with omeprazole iv $(\mathrm{p}<0.05)$ (Table 3$)$. There was a significant difference between the average cost of these two drugs, approximately 174,859 IDR. This finding was slightly different from previous research conducted by Udeh et al. [16]; the results showed that pantoprazole was ranked third for the average highest cost, i.e., $\$ 514.07$ after cimetidine iv (\$633.25) and sucralfate (\$579.42) as prophylaxis of stress ulcer.

From the unit cost aspect, the cost of both the injection has no big differences. It is only around 10,129 IDR. However, when saw from the average cost, there were a significant difference in average drug costs. It was likely caused by the amounts of drugs given to patients in a day. Pantoprazole iv in general is given once a day as a prophylactic for ICU patients while sometimes omeprazole iv is given twice a day for patients with severe conditions [17]. Other factors that may affect the cost difference was the length of prophylaxis usage. Based on the patient's medical record the time SUP usage is quite diverse. Schupp et al. [7] used some parameters to control SUP usage, e.g., hematemesis, melena, bloody/nasogastric aspirate ground coffee, a decrease in hemoglobin of $3 \mathrm{~g} / \mathrm{dl}$ with hemodynamic.

Heidelbaugh et al. [18] stated that the use of PPI should be controlled as well as it can cause side effect to the patient especially in case of excessive use (overutilization). Overutilization is a factor that can increase medication cost and if the side effects due to overutilization it will have an impact on the increasing of the maintenance costs of the patient [19].
Using retrospective data are a limitation of this study. Therefore, it can lead to recall bias during data justification. However, the researchers also gathered prospective data as a combination data and also reference so the recall bias can be minimized.

\section{CONCLUSION}

Both pantoprazole iv and omeprazole iv were effective, but pantoprazole iv had been found more cost minimize.

\section{ACKNOWLEDGMENT}

The authors thank Mrs. Rani Ratnawati for her assistance during this research.

\section{REFERENCES}

1. Stollman N, Metz D. Pathophysiology and prophylaxis of stress ulcer in intensive care unit patients. J Crit Care 2005;20:35-45.

2. MacLaren R, Campbell J. Cost effectiveness of histamine receptor-2 antagonist versus proton pump inhibitor for stress ulcer prophylaxis in critically ill patients. Crit Care Med 2014;42(48):9-15.

3. Barletta J, Erstad B, Fortune J. Stress ulcer prophylaxis in trauma patients. Ctit Care 2002;6(6):526-30.

4. AHSP. Therapeutic guidelines on stress ulcer prophylaxis. Am J Health Syst Pharm 1999;56:347-79.

5. Cook D, Griffith L, Walter S, Guyatt G, Meade M, Heyland D. The attributable mortality and length of intensive care unit stay of clinically important gastrointestinal bleeding in critically ill patients. Crit Care Med 2001;5(6):368-75

6. Harty R, Ancha H. Stress ulcer bleeding. Curr Treat Options Gastroenterol 2006;9:157-66.

7. Schupp K, Schrand L, Mutnick A. A cost effectiveness analysis of stress ulcer prophylaxis. Ann Pharmacother 2003;37:631-5

8. Barkun A, Adam V, Martel M, Bardou M. Cost effectiveness analysis: Stress ulcer bleeding prophylaxis with proton pump inhibitors, H2 receptor anatagonist. Value Health 2013;16:14-22.

9. Barletta J, Sclar D. Use of proton pump inhibitors for the provision of stress ulcer prophylaxis: Clinical and economic consequences. Pharmacoeconomics 2014;32:5-13.

10. Araujo T, Vieira S, Carvalho P. Stress ulcer prophylaxis in pediatric intensive care units. J Pediatr (Rio J) 2010;88(6):525-30.

11. Madsen K, Lorentzen K, Clausen N, Øberg E, Kirkegaard PR, Maymann-Holler N. Guideline for stress ulcer prophylaxis in the intensive care unit. Dan Med J 2014;61(3):4811.

12. Quenot J, Thiery N, Barbar S. When should stress ulcer prophylaxis be used in the ICU? Curr Opin Crit Care 2009;15(2):139-43.

13. Macdonald J, Roberts J, Washington S. Stess ulcer prophylaxis: Friend or foe? Br J Hosp Med (Lond) 2012;73(4):238.

14. Rascati K. Essentials of Pharmacoeconomic. Baltimore: Lippincott Williams \& Wilkins; 2009.

15. Cunningham S. An introduction to economic evaluation of health care. Curr Prod Pract 2001;28(3):246-50.

16. Udeh B, Udeh C, Hata J. Cost effectiveness of stree ulcer prophylaxis: Role of proton pump inhibitors. Am J Pharm Benefit 2010;2(5):304-12.

17. van Hout B, Klok R, Brouwers J, Postma M. A pharmacoeconomic comparison of the efficacy and costs of pantoprazole and omeprazole for the treatment for peptic ulcer or gastroesophageal reflux disease in the Netherlands. Clin Ther 2003;25(2):635-46.

18. Heidelbaugh $\mathrm{J}$, Goldberg K, Inadomi J. Overutilization of proton pump inhibitors: A review of cost effectiveness and risk in PPI. Am J Gastroenterol 2009;104:27-32.

19. Cahir C, Fahey T, Tilson L, Teljeur C, Bennett K. Proton pump inhibitors: Potential cost reductions by applying prescribing guidelines. BMC Health Serv Res 2012;12:408. 